\title{
High postoperative monocyte indicates inferior Clinicopathological characteristics and worse prognosis in lung adenocarcinoma or squamous cell carcinoma after lobectomy
}

Yang Hai ${ }^{1,2+}$, Nan Chen ${ }^{1,2+}$, Wenwen $\mathrm{Wu}^{2}$, Zihuai Wang ${ }^{2}$, Feng Lin ${ }^{1}$, Chenglin Guo ${ }^{1}$, Chengwu Liu', Weimin Li ${ }^{3}$ and Lunxu Liu ${ }^{1,2^{*}}$

\begin{abstract}
Background: Peripheral monocyte count is an assessable parameter. Recently, evidence suggested an elevated preoperative monocyte counts predicting poor prognosis in malignancies. The aim of this study was to determine the prognostic effect of early postoperative blood monocyte count in patients with lung adenocarcinoma or squamous cell carcinoma following lobectomy.

Methods: We retrospectively reviewed patients with operated lung adenocarcinoma or squamous cell carcinoma from 2006 to 2011 in Western China Lung Cancer database. Univariate analysis on disease-free survival (DFS) and overall survival (OS) was performed using the Kaplan-Meier and log-rank tests, and multivariate analysis was conducted using the Cox proportional hazards regression model.

Results: There were 433 patients enrolled in our analysis. High postoperative elevated monocyte was associated with male gender $(P<0.001)$, positive smoking history $(P=0.005)$, and higher $N$ stage $(P=0.002)$ and higher tumor stage $(P=0.026)$. Two-tailed log-rank test indicated patients with an early postoperative elevated monocyte count predicted a poor DFS and OS overall $(P<0.001, P<0.001$, respectively) as well as in subgroup analysis, and further presented as a promising independent prognostic factor for both DFS and OS $(\mathrm{HR}=2.991,95 \% \mathrm{Cl}: 2.243-3.988, P<0.001 ; \mathrm{HR}=2.705,95 \% \mathrm{Cl}: 1.977-3.700, P<0.001$, respectively) on multivariate analysis. However, no significance was detected for preoperative monocyte in multivariate analysis.
\end{abstract}

Conclusions: Elevated early postoperative peripheral monocyte count was an independent prognostic factor of poor prognosis and inferior clinicopathological features for patients with operable lung adenocarcinoma or squamous cell carcinoma by lobectomy.

Keywords: Lung squamous carcinoma, Lung adenocarcinoma, Peripheral monocyte count, Prognosis

\footnotetext{
* Correspondence: lunxu_liu@aliyun.com

†Yang Hai and Nan Chen contributed equally to this work.

'Department of Thoracic Surgery, West China Hospital, Sichuan University,

Address: No. 37, Guoxue Alley, Chengdu 610041, Sichuan, China

${ }^{2}$ West China School of Medicine, Sichuan University, Chengdu 610041, China

Full list of author information is available at the end of the article
}

(c) The Author(s). 2018 Open Access This article is distributed under the terms of the Creative Commons Attribution 4.0 International License (http://creativecommons.org/licenses/by/4.0/), which permits unrestricted use, distribution, and reproduction in any medium, provided you give appropriate credit to the original author(s) and the source, provide a link to the Creative Commons license, and indicate if changes were made. The Creative Commons Public Domain Dedication waiver (http://creativecommons.org/publicdomain/zero/1.0/) applies to the data made available in this article, unless otherwise stated. 


\section{Background}

Lung cancer is the leading cause of cancer-related death worldwide, with 5-year survival rates of less than $17 \%$ [1]. Non-small-cell lung cancer (NSCLC) accounts for approximately $85 \%$ of all lung cancers. NSCLC is further subtyped into adenocarcinoma and squamous cell carcinoma, which respectively account for approximately $40 \%$ and $25-30 \%$ of lung cancers $[1,2]$. If operable, surgery provides the best chance to cure NSCLC [3]. There is a need for a comprehensive perioperative evaluation system for this deadly disease.

The interplay between cancer and inflammation was postulated back in the late nineteenth century, and even today continues to be an active area of research. [2]. Such research often focus on the effects of tissue necrosis factor (TNF), interleukin (IL)-1, IL-6, matrix metalloproteinases, vascular endothelial growth factor, etc. However, peripheral blood cells, monocytes/macrophages, neutrophils, dendritic cells, and natural killer cells form the first line of immune defense in normal situations [4]. Recently, elevated preoperative monocyte counts have recently been shown to predict poor prognosis in various types of malignancies, including hepatic cell carcinoma, malignant lymphomas as well as lung adenocarcinoma [5-7]. However, it is still unclear if an elevated early postoperative monocyte count was associated with a poor prognosis in lung adenocarcinoma or squamous cell carcinoma after lobectomy.

We focused on the early postoperative period because it is the most turbulent stage of the host immune system which may be caused by the surgical trauma and/or tumor removal effect, and we hypothesized that this change in immune environment is related with tumor progression. The aim of this study was to evaluate whether an elevated early postoperative monocyte count predicted a poor prognosis in patients with operable lung adenocarcinoma or squamous cell carcinoma after lobectomy.

\section{Methods}

\section{Study population}

The data were retrieved from Western China Lung Cancer database (WCLC). We enrolled patients with operable lung adenocarcinoma or squamous cell carcinoma treated with lobectomy at West China Hospital, Sichuan University between 2006 and 2011. All patients were > 18 years of age, with complete clinicopathological data, and proven to be lung adenocarcinoma or squamous cell carcinoma after surgery. Preoperative evaluation included physical examination, blood routine examination, tumor markers test, chest X-ray and computed tomography, brain magnetic resonance imaging (MRI), bone scintigraphy, and bronchoscopy and integrated positron emission tomography scan and CT (PET/CT) scan when necessary. The eligibility criteria were: 1 ) lobectomy with no microscopic residual tumor; 2) no preoperative chemotherapy and/or radiotherapy; 3) no previous history of other malignancies; 4) no evidence of infections such as pneumonia; 5) availability of laboratory data and follow-up information. All peripheral venous blood samples were collected from patients within 1 week before and 4 days after surgery. If multiple post-operative blood samples were drawn, only the first sample after surgery was used for analysis. Absolute peripheral blood count and the percentage were analyzed for each blood sample. Histological classification was made with reference to the latest WHO guideline [8]. The stages of lung cancer were confirmed based on the 7th edition of TNM classification of malignant tumors [9]. Study approval was granted by the Institutional Review Board at the West China Hospital, Sichuan University.

\section{Evaluation of clinicopathological factors}

Baseline characteristics included age, sex, underlying diseases, smoking history, pathological stage, pathological tumor status, pathological lymph node status, and peripheral blood counts and the percentages. Blood samples analysis were performed within the clinical laboratory of our hospital with a Cell-Dyn 3700 (Abbott Diagnostics, USA). Other data included the surgical date and procedures.

\section{Treatment and follow-up}

Lobectomy was performed on all patients with intent to cure, and systematic nodal dissection was carried out. The resection was done both macroscopically and histologically with a negative tumor margin and no evidence of distant metastasis. Patients were regularly followed up at outpatient department 1 month after surgery, every 3 months for the first year, every 6 months for the next 4 years, and once annually thereafter. Patients received a physical examination, blood routine examination, chest and brain and upper abdomen CT scan at each follow-up. Bone scintigraphy was performed every 12 months. In particular, all patients treated in our department received phone call follow-up regularly, during which we recorded their living status, tumor recurrence/metastasis condition, and any adjuvant therapy such as chemotherapy and/or radiotherapy, etc. The patients were followed until August 31,2017 or until they died.

\section{Statistical analysis}

Receiver operating characteristic (ROC) curve was performed to obtain the best cut-off value for monocyte count to stratify patients at a high risk of tumor recurrence, distant metastasis, or death. In the ROC curve, the point with the maximum sensitivity and specificity was selected as the best cut-off value. Disease-free 
survival (DFS) was calculated from the date of surgery to the date of recurrence/metastasis or death with any cause, and overall survival (OS) was presented from the date of surgery to the date of death with any cause. Fisher's exact test or $x^{2}$-test for categorical variables and $t$-test for continuous variables were used to analyze the clinicopathological features for the two groups divided by the cut-off value of monocyte. A life table was made to calculate 1, 3 and 5-year survival rate. Survival curves were plotted using the Kaplan-Meier method and compared using the log-rank test. The prognostic factors of OS and DFS were analyzed by Cox proportional hazard model with univariate and multivariate analysis. Factors significant in the univariate analysis were included in the multivariate analysis. Subgroup analysis was used to further discriminate tumor prognosis between monocyte count and other prognostic factors: pathological stage, histological type, etc. All $P$ values were two-tailed with less than 0.05 considered to be statistically significant. Statistical analysis was performed using SPSS (SPSS version 19.0, Chicago, IL, USA) and STATA 14.0 (STATA Corporation, College Station, TX, USA). Survival curves were drawn by GraphPad Prism 5.0 (GraphPad Software, San Diego, CA).

\section{Results}

Retrospective study selection process

The selection process of patients was shown in Fig. 1 . There were 1665 patients identified in total. 1232 patients were excluded for cancer type, pathological stage, or surgical procedure mismatch, previous history of malignancies or chemotherapy/radiotherapy, and those

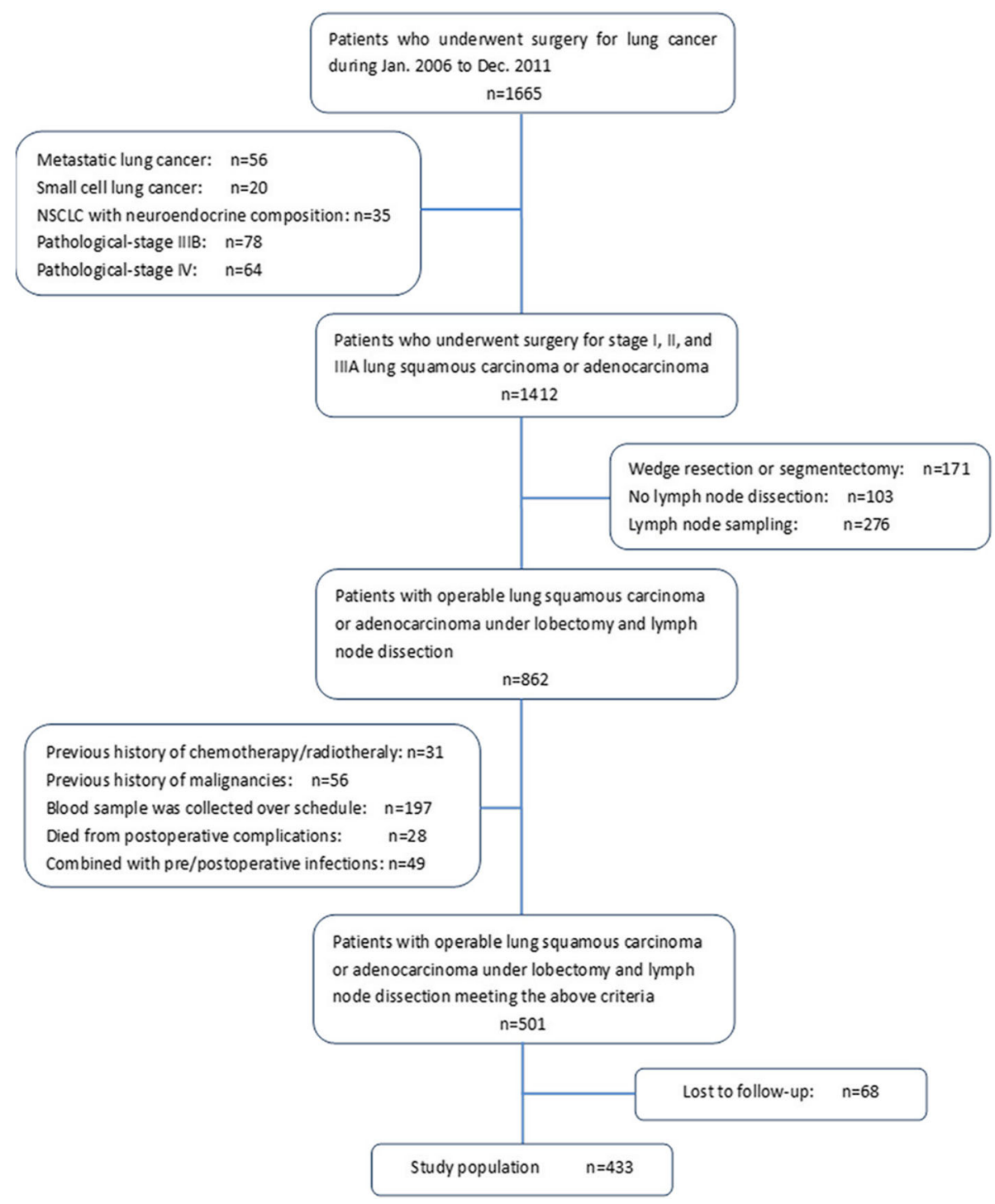

Fig. 1 Flow chart of patient selection 


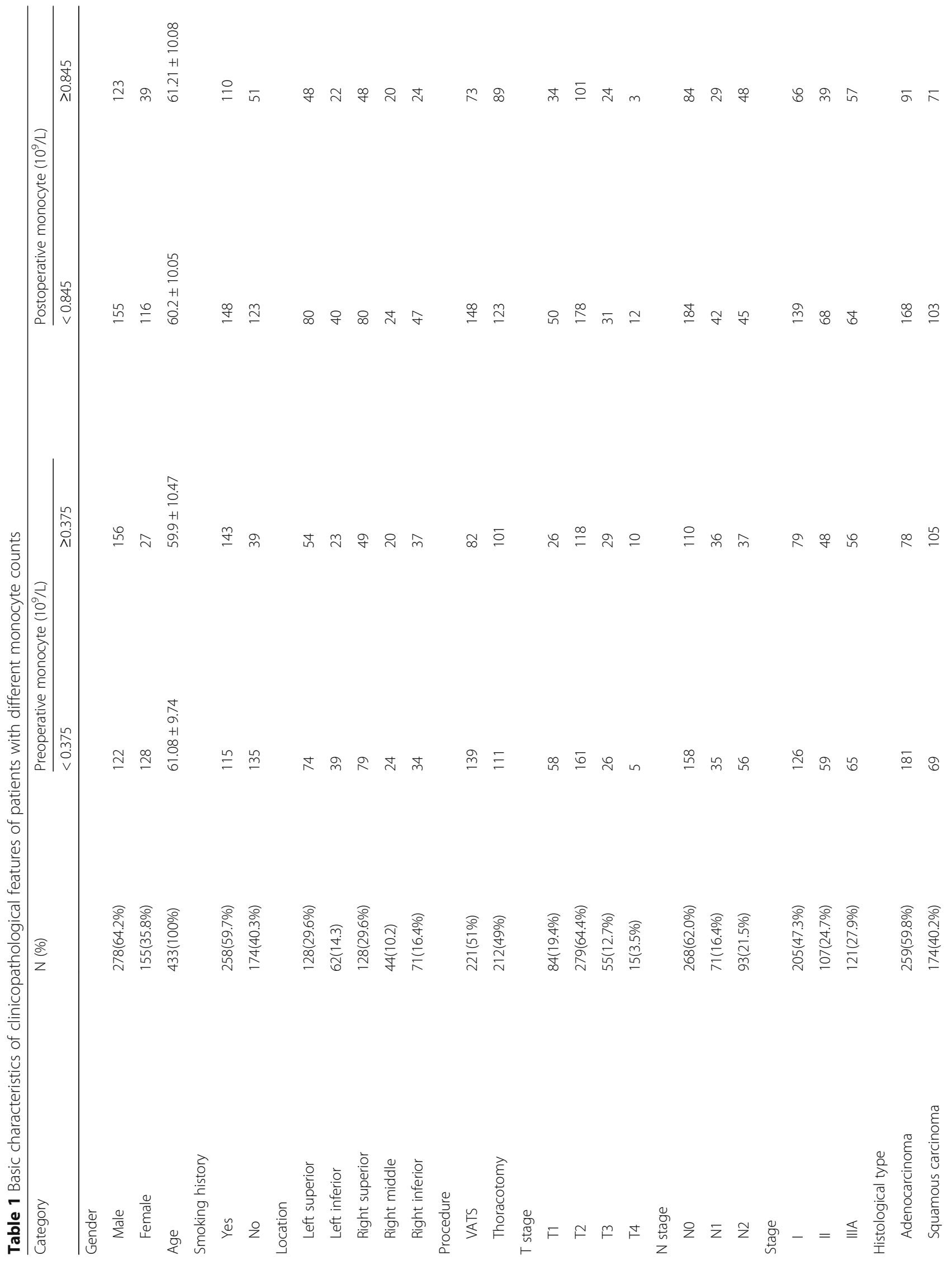




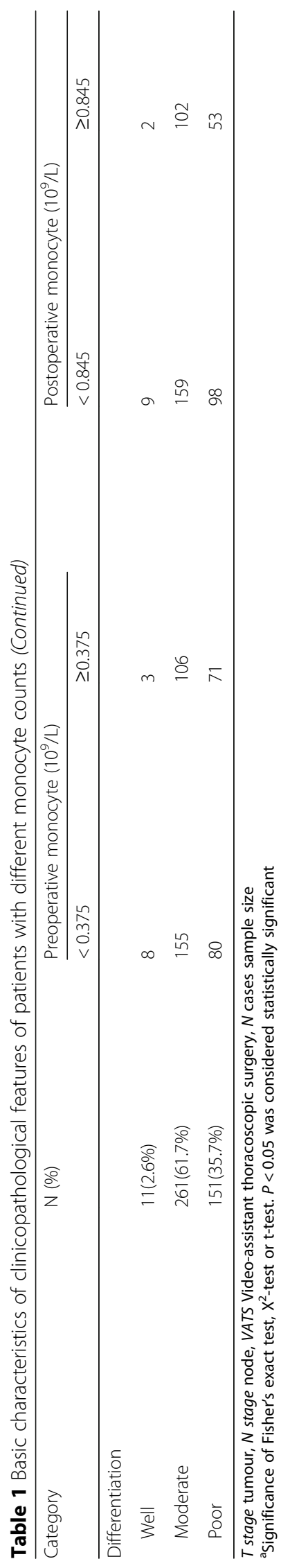


co-morbid with infections. There were 433 patients enrolled in our analysis. The average age and standard deviation for the 433 patients were 60.6 and 10.0, respectively. Among them, there were 278(64.2\%) males and $155(35.8 \%)$ females. Video-assisted thoracic surgery (VATS) was performed in 221(51.0\%) patients compared with traditional thoracotomy surgery in $212(49.0 \%)$ patients. Specimens were histologically proven to be lung adenocarcinoma in $264(61.0 \%)$ patients and squamous cell carcinoma in 169(39.0\%) patients. Details are presented in Table 1.

\section{Cut-off selection for monocyte counts and survival rate calculation}

By analyzing the ROC curve, the cut-off value for preoperative monocyte count was $0.375 * 10^{9} / \mathrm{L}$ with the area under the curve (AUC) of 0.566; while for postoperative monocyte count, the cut-off value was $0.845^{*} 10^{9} / \mathrm{L}$ with AUC of 0.692 (Fig. 2). The baseline characteristics were stratified by high versus low preoperative monocyte and early postoperative monocyte count (Table 1 ).

We then performed the Kaplan-Meier method to identify difference of survival rates between two groups stratified by monocyte count (low vs. high) of both preoperative and early postoperative group.

\section{Preoperative group OS and DFS}

The 1-year OS of low and high subgroups were $95 \%$ and 93\% $(P=0.003)$, and the 1 -year DFS of low and high subgroups were $82 \%$ and $85 \%(P=0.106)$. The 3 -year OS of low and high subgroups were $82 \%$ and $74 \%(P=0.003)$, and the 3-year DFS of low and high subgroups were $67 \%$ and $60 \%(P=0.106)$, respectively. Additionally, the 5-year OS of low and high subgroups were $72 \%$ and $58 \%(P=$ $0.003)$, and the 5-year DFS of low and high subgroups were $62 \%$ and $51 \%(P=0.106)$. However, when stratified by gender, age, smoking history, stage, $\mathrm{T}$ stage, $\mathrm{N}$ stage

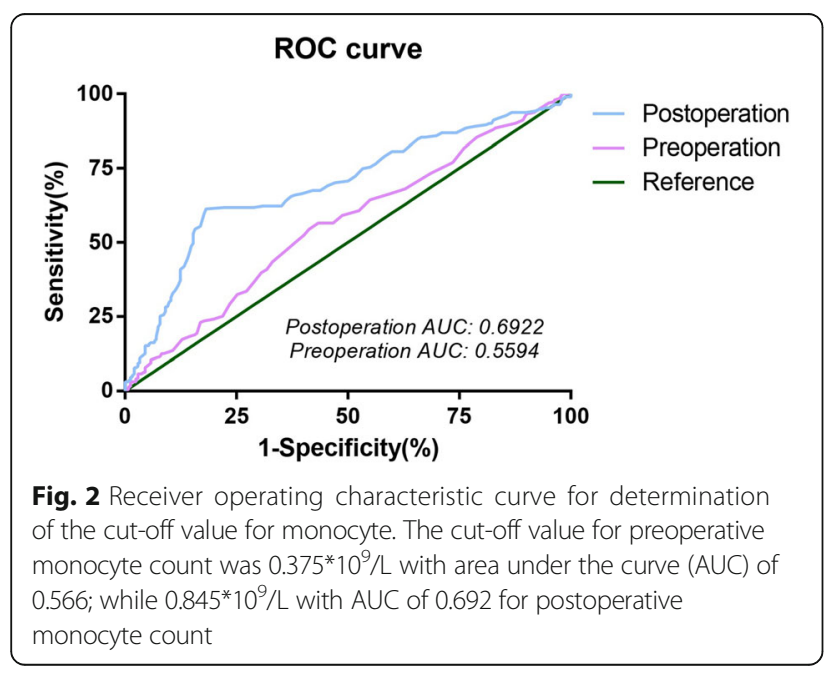

and surgical procedure, no statistical significance were seen in subgroup study of the preoperative group.

\section{Early postoperative group OS and DFS}

The 1-year OS of low and high subgroups were 96\% and $90 \%(P=0.004)$, and the 1 -year DFS of low and high subgroups were $90 \%$ and $71 \%(P<0.001)$. The 3 -year OS of low and high subgroups were $89 \%$ and $62 \%(P<0.001)$, and the 3 -year DFS of low subgroup was $78 \%$ compared to $41 \%$ in high group $(P<0.001)$. In addition, the 5-year OS of low and high subgroups were $79 \%$ and $46 \%(P<0.001)$, and the 5 -year DFS of low and high subgroups were $72 \%$ and $33 \%(P<0.001)$. Overall, an early postoperative elevated monocyte count was significantly associated with poor OS $(P<$ $0.001)$ and DFS $(P<0.001)$ (Fig. 3$)$. In further analysis, high level postoperative monocyte count was associated with poor OS and DFS in both adenocarcinoma and squamous carcinoma subgroups (Fig. 4). These differences were also significant in subgroup analysis when stratified by gender, age, smoking history, stage, $\mathrm{T}$ stage, $\mathrm{N}$ stage and surgical procedure in postoperative group (Figs. 5, 6).

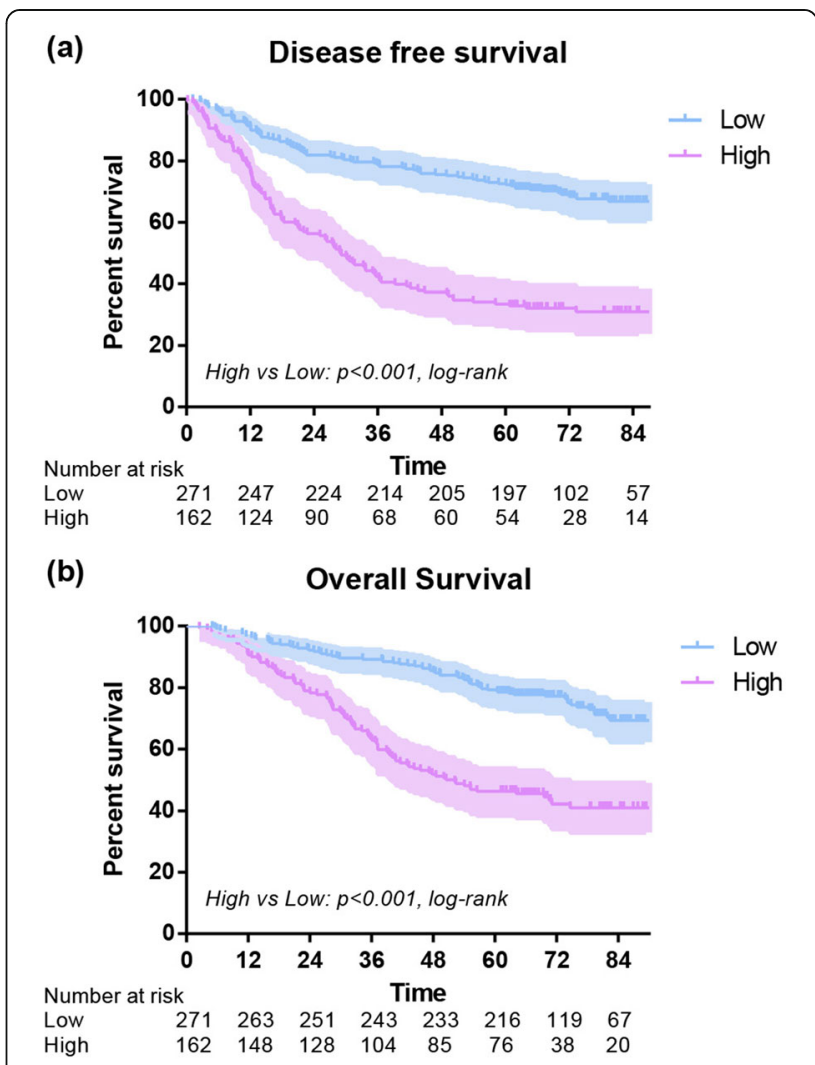

Fig. 3 Disease-free survival (a) and overall survival (b) of high and low postoperative monocyte level 

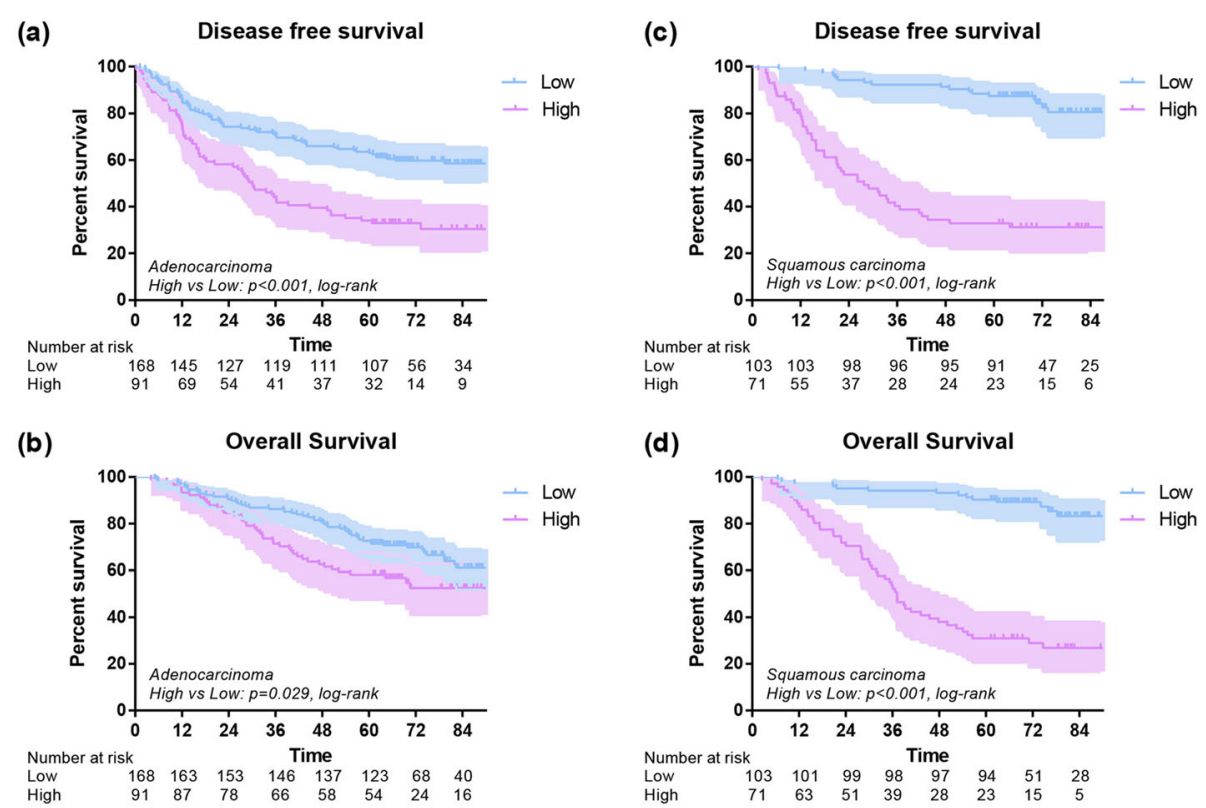

Fig. 4 Disease-free survival and overall survival of 433 lung cancer patients with different monocyte stratified by histological type of adenocarcinoma $(\mathbf{a}, \mathbf{b})$ and squamous cell carcinoma $(\mathbf{c}, \mathbf{d})$

\section{Univariate analysis}

Univariate prognostic analysis was performed to detect the prognostic significance of clinicopathological factors, and preoperative and early postoperative blood monocyte count (Table 2$)$. N stage $(P<0.001)$, tumor stage $(P<0.001)$, histological type $(P=0.014)$, preoperative $(P=0.023)$ and postoperative monocyte count level $(P<0.001)$ were significantly associated with DFS, while age $(P=0.017)$, surgery procedure $(P$ $=0.002), \mathrm{T}$ stage $(P=0.003), \mathrm{N}$ stage $(P<0.001)$, tumor stage $(P<0.001)$, preoperative $(P=0.024)$ and postoperative monocyte count level $(P<0.001)$ showed significant relationships with OS.

\section{Multivariate analysis}

The clinicopathological factors proved to be prognostic predictors in univariate analysis were included as covariates in further multivariate analysis (Table 3). Finally, thoracotomy $(\mathrm{HR}=1.520,95 \% \mathrm{CI}: 1.117-2.069$, $P=0.008)$, positive $\mathrm{N}$ status $(\mathrm{HR}=2.506, \quad 95 \% \mathrm{CI}$ : $1.625-3.864, \mathrm{P}<0.001)$, Adenocarcinoma $(\mathrm{HR}=2.273$, 95\%CI: $1.181-4.374, P=0.014)$ and high postoperative monocyte count $(\mathrm{HR}=2.991,95 \% \mathrm{CI}: 2.243-3.988, P<$ $0.001)$ were risk factors with statistical significance for DFS. Correspondingly, age $(\mathrm{HR}=1.022$, 95\%CI: $1.005-$ 1.038, $P=0.009)$, thoracotomy $(\mathrm{HR}=1.700,95 \% \mathrm{CI}$ : $1.163-2.486, P=0.006)$, advanced tumor stage $(\mathrm{HR}=$ 2.253, 95\%CI: $1.178-4.309, P<0.001)$, and high postoperative monocyte count $(\mathrm{HR}=2.705$, 95\%CI: $1.977-$ 3.700, $P<0.001$ ) were observed as risk factors for OS. However, preoperative monocyte was no more associated with either DFS or OS within multivariate analysis.

\section{Discussion}

Immune response is an essential component of tumor progression. Studying the immune factors expressed in the tumor microenvironment can further stratify the prognosis of cancer [10]. Back in 1997, Negus et al. had demonstrated that a number of cells expressing chemokine receptors could infiltrate to tumor areas [11]. Since then, various experimental studies have elucidated identities of these chemokines. Inflammatory markers such as C-reactive protein in esophageal squamous cancer [12], Colony-stimulating factor-1 in mammary tumor [13], and inhibitors of metalloproteinases in NSCLC [14], all have been suggested as alternative markers for tumor progression [8]. Meanwhile, the peripheral blood cell counts, an easily assessible biomarker, has also been suggested as predictors of tumor prognosis. An elevated neutrophil, monocyte and leukocyte counts were proven to be associated with poor survival in patients with metastatic melanoma [15].

High pre-operative monocyte count associated with poor survival following surgical procedures

Monocytes belonged to circulating peripheral blood cells that played the crucial role in immune response with the capability of differentiating into macrophages and antigen-presenting cells (APCs). Thus, they formed the first line of innate immune defense [16]. 

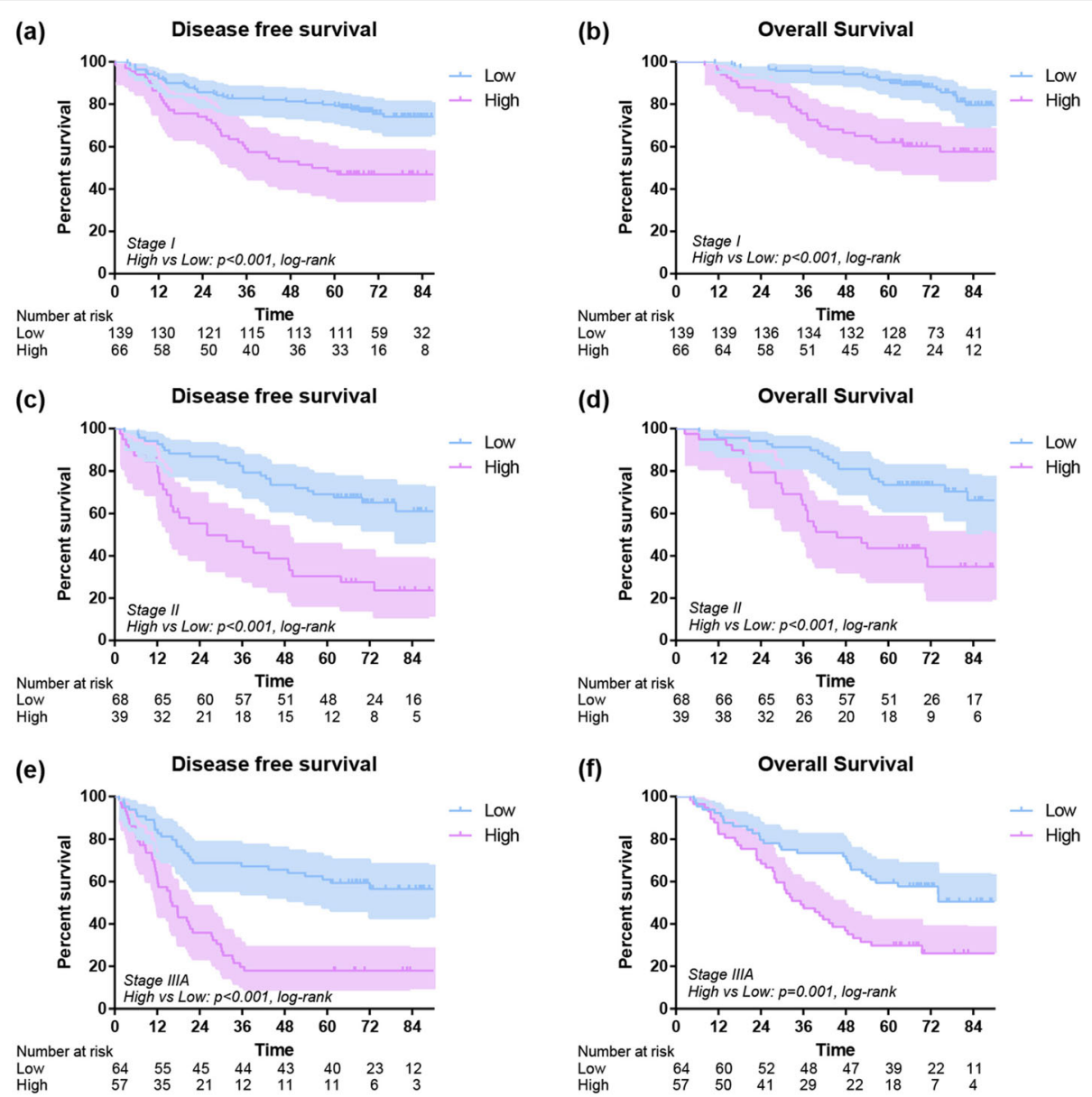

Fig. 5 Disease-free survival and overall survival of 433 lung cancer patients with different monocyte stratified by tumor stage(stage I disease: $\mathbf{a}$, b; stage II disease: $\mathbf{c}$, $\mathbf{d}$; stage IIIA disease: $\mathbf{e}, \mathbf{f}$ )

In addition, monocytes could activate $\mathrm{T}$ and $\mathrm{B}$ lymphocytes and further produce cytokines such as IL-12 and TNF- $\alpha$ to stimulate the immune response [17]. However, either overstimulation or immunosuppression of monocytes caused by surgical procedure and/ or other external factors could disrupt the immune system $[18,19]$. Previous studies have shown an elevated preoperative monocyte count to be a poor prognostic factor in esophageal squamous cell carcinoma, mantle cell lymphoma, follicular lymphoma, and classical Hodgkin lymphoma, respectively $[6,7,20,21]$. During the early postoperative period, absolute monocyte count is increased but monocyte function is impaired, as demonstrated by a decreased ability to synthesize IL- 12 and TNF- $\alpha$, to express HLA-DR, and to act as the APC [22]. To the best of our knowledge, this is the first study suggesting the prognostic significance of the early postoperative monocyte count in patients with lung adenocarcinoma or squamous cell carcinoma after lobectomy.

\section{Postulated pathophysiologic mechanisms of monocyte proliferation in tumors}

The mechanism of elevated monocyte count and poor prognosis of several kinds of tumors is still unclear, despite several proposed postulations. First, it was hypothesized that monocytes are attracted by several cytokines or chemokines to the tumor site and then differentiated into tumor-associated macrophages (TAMs), which further promoted those invading leukocytes to bring out potentials of angiogenesis, motility, and invasion [23, 24]. Angiogenic signals from surrounding cells resulted in vasodilatation and increased vascular permeability $[25,26]$, forming a vicious cycle for tumor progression. Second, human monocyte subsets were differentiated according to their surface CD14/CD16 expression as "majority/classical" (CD14++CD16-), "minority/non-classical" $(\mathrm{CD} 14+\mathrm{CD} 16+)$ and the subset with pro-angiogenic feature (CD14++CD16+CCR2+) [27, 28]. Among all subsets of the monocytes, the "majority/classical" 

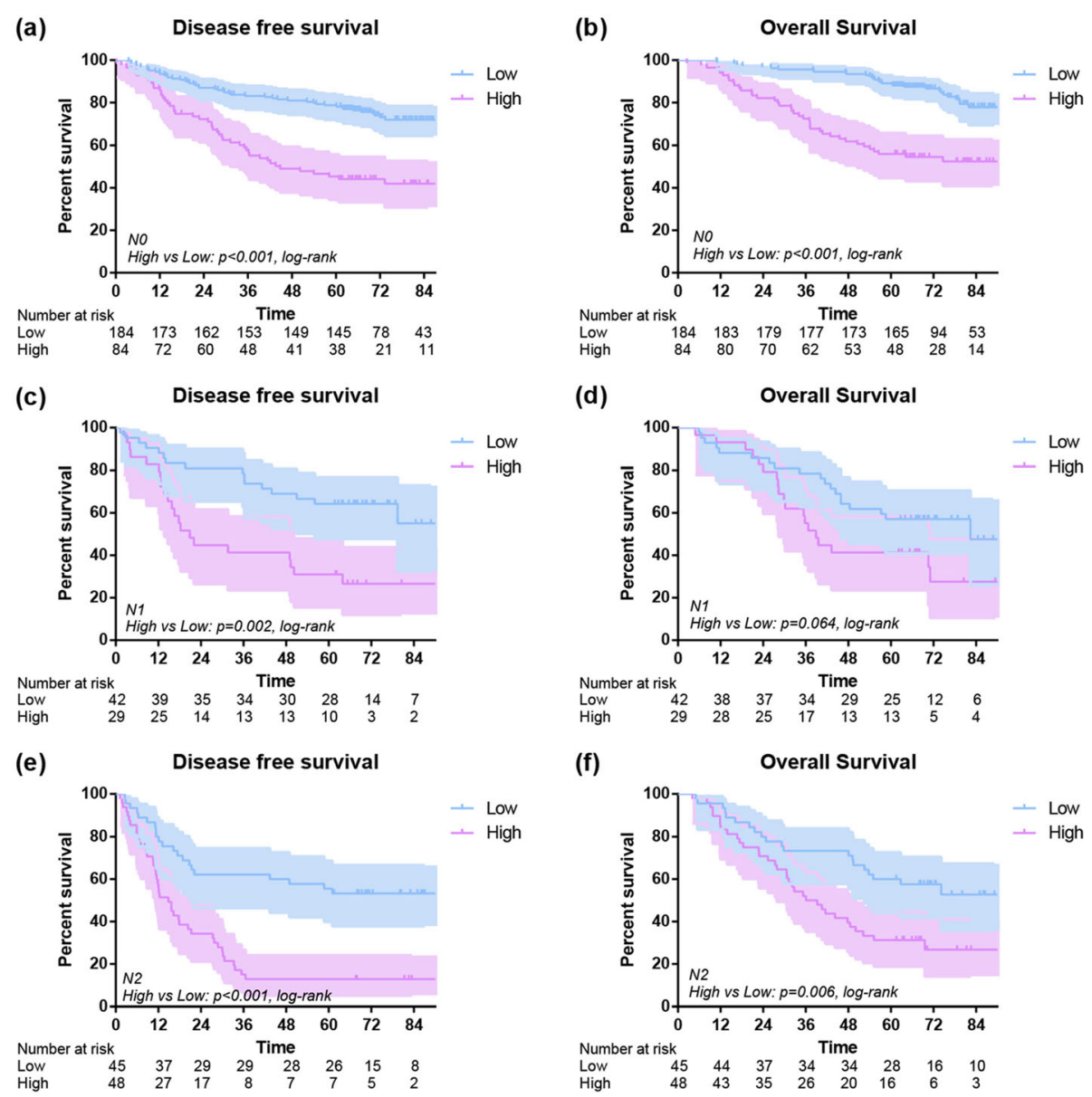

Fig. 6 Disease-free survival and overall survival of 433 lung cancer patients with different monocyte stratified by N stage(N0 stage: $\mathbf{a}$, b; N1 stage: c, d; N2 stage: e, f)

accounts for approximately $90 \%$ of monocytes in healthy people [29]. However, Schauer et al. found that along with the increased number of monocytes, the major monocyte population shifted from CD16- to $\mathrm{CD} 16+$ after liver resection, showing a stronger potential of angiogenesis [30].

\section{Macrophages types M1 and M2 and monocytes in post- operative patient}

It is known that classical monocytes are recruited to tumor sites, contributing to tumor macrophage content and promoting tumor growth and metastasis [31]. Meanwhile, Hanna et al. also found out the potential protective role of nonclassical "patrolling" monocytes on tumor growth and metastasis [32]. This was also our next step to find out whether it will happen after lobectomy of lung cancer and what the exact type was and the alternatives of the function in immunity. Third, peripheral monocytes grow into TAMs when entering tumor areas. TAMs are classified into two phenotypes: M1 and M2. Activated M1 macrophages have the anti-tumor response, while M2 macrophages, activated by tumor-derived cytokines, were suitable for tumor development [33, 34]. A previous study has reported that circulating macrophages predict tumor recurrence after surgery in patients with NSCLC [35], while in this study, an elevated early postoperative peripheral monocyte count was significantly associated with a poor prognosis in patients with lung adenocarcinoma or squamous cell carcinoma after lobectomy. These results suggest a complex association between peripheral TAMs (M2 type) and monocytes, though further studies are needed to verify this. Moreover, the reason why we focused on the early postoperative period - the most turbulent stage of host immune system caused by surgical trauma and/or tumor removal effect - was that we hypothesized that immune environment changes in the early post-op period might relate with tumor progression more closely than that of the preoperative period. 


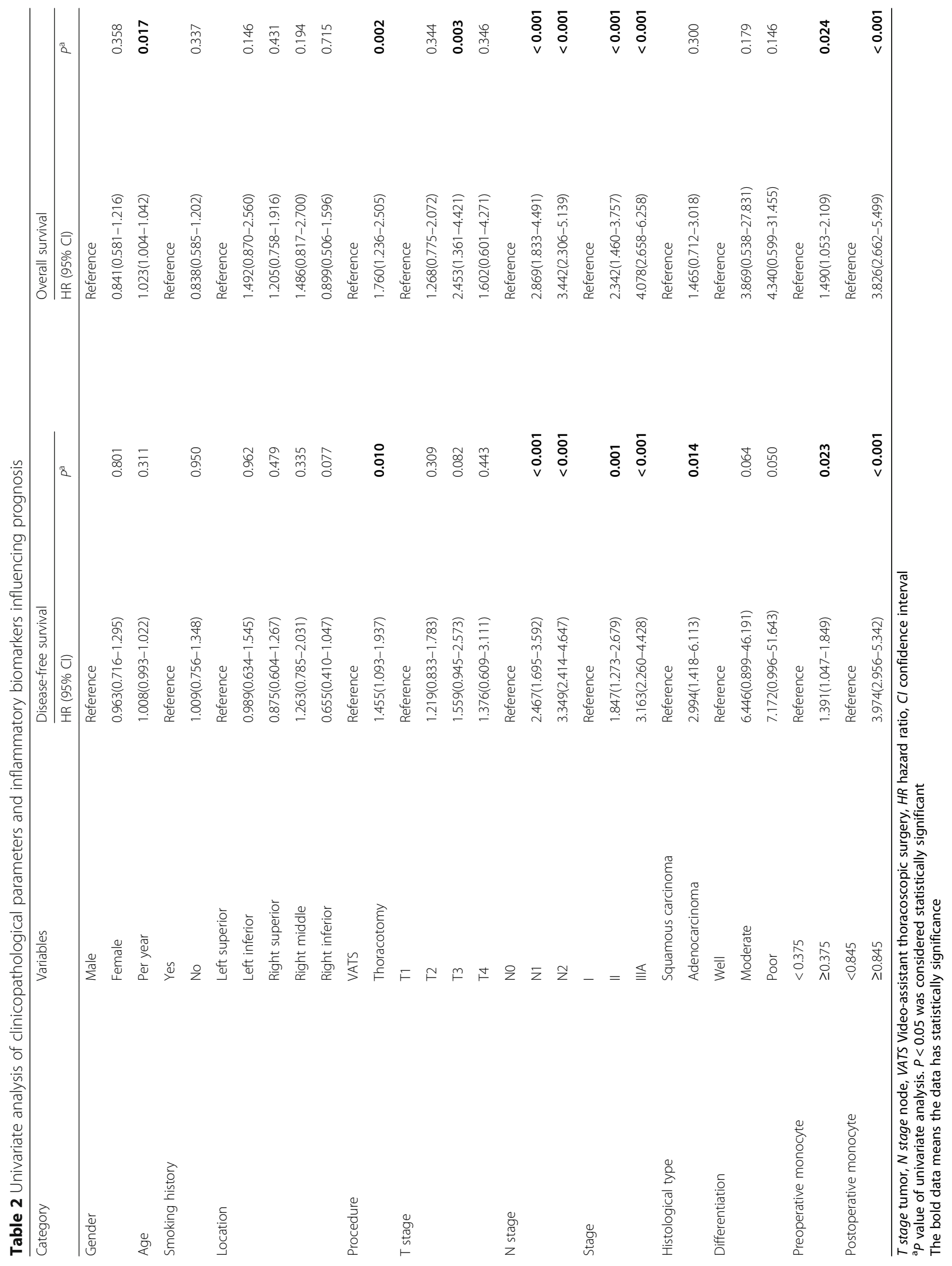


Table 3 Multivariate analysis of clinicopathological parameters and inflammatory biomarkers influencing prognosis

\begin{tabular}{|c|c|c|c|}
\hline Category & Variables & HR $(95 \%$ Cl) & $P^{a}$ \\
\hline \multicolumn{4}{|l|}{ Disease-free survival } \\
\hline \multirow[t]{2}{*}{ Procedure } & VATS & Reference & \\
\hline & Thoracotomy & $1.520(1.117-2.069)$ & 0.008 \\
\hline \multirow[t]{3}{*}{ N stage } & No & Reference & \\
\hline & N1 & $2.319(1.584-3.396)$ & $<0.001$ \\
\hline & N2 & $2.584(1.845-3.620)$ & $<0.001$ \\
\hline \multirow[t]{2}{*}{ Histological type } & Squamous carcinoma & Reference & \\
\hline & Adenocarcinoma & $2.273(1.181-4.374)$ & 0.014 \\
\hline \multirow[t]{2}{*}{ Postoperative monocyte } & $<0.845$ & Reference & \\
\hline & $\geq 0.845$ & $3.684(2.729-4.975)$ & $<0.001$ \\
\hline \multicolumn{4}{|l|}{ Overall survival } \\
\hline Age & Per year & $1.034(1.014-1.054)$ & 0.001 \\
\hline \multirow[t]{2}{*}{ Procedure } & VATS & Reference & \\
\hline & Thoracotomy & $1.700(1.163-2.486)$ & 0.006 \\
\hline \multirow[t]{3}{*}{ Stage } & । & Reference & \\
\hline & $\|$ & $2.228(1.383-3.592)$ & 0.001 \\
\hline & $\| \mathrm{A}$ & $3.592(2.327-5.546)$ & $<0.001$ \\
\hline \multirow[t]{2}{*}{ Postoperative monocyte } & $<0.845$ & Reference & \\
\hline & $\geq 0.845$ & $3.403(2.362-4.902)$ & $<0.001$ \\
\hline
\end{tabular}

$N$ stage node, VATS Video-assistant thoracoscopic surgery, $\mathrm{HR}$ hazard ratio, $\mathrm{Cl}$ confidence interval

${ }^{\text {a }} P$ value of multivariate analysis. $P<0.05$ was considered statistically significant

The bold data means the data has statistically significance

\section{Present study associates elevated early postoperative monocyte counts with poor survival}

In the present study, an elevated early postoperative monocyte count was shown to predict a poor DFS and OS both in the univariate and multivariate analysis. In addition, as shown in the subgroup analysis, the monocyte count was found to be significantly associated with poor prognosis when stratified by gender, age, smoking history, TNM stage, surgical procedure and histological type. All of the above indicated that an elevated early postoperative blood monocyte count to be a very strong prognostic factor in tumor progression.

\section{Limitations of current study}

Limitations of the current study are inherent to its design, including the retrospective data collection and several confounding factors when comparing postoperatively. For example, a t-test performed from Table 1 shows an association of male gender with a high post-operative monocyte count. Similarly, smoking is associated with a high post-operative monocyte count. However, since male smokers outnumber female smokers in China [36], and most of the patients in our lung cancer clinic are male smokers, there is no way to untangle these two factors in a retrospective study. Or perhaps, an unidentified factor may influence both male gender and smoking independently to cause monocyte count increase. A prospective study may be able to control for these confounders. Moreover, the small number of patients, especially the cases with endpoints, also limited the conclusion of the current study.

\section{Cautious and prudent monitoring}

Although there is no evidence currently to change the management of patients following a lobectomy, we are reporting some prognostic significance of the postoperative monocyte count on survival. The increased mortality for patients with elevated early postoperative monocyte, particularly in patients with squamous cell carcinoma, warrants a cautious approach to monitor disease progression.

\section{Conclusion}

The present study supported the prognostic significance of early postoperative peripheral blood monocyte count in patients with operable lung adenocarcinoma or squamous cell carcinoma after lobectomy in both OS and DFS. This easily measured blood parameter may provide useful information for the clinicians to stratify patients. Further investigations will be needed to figure out the oncological significance of monocyte and its subsets, and the association with the host inflammatory microenvironment. 


\section{Abbreviations}

APCs: Antigen-presenting cells; AUC: Area under the curve; DFS: Disease-free survival; IL: Interleukin; MRI: Magnetic resonance imaging; NSCLC: Non-small cell lung cancer; OS: Overall survival; PET-CT: Positron emission tomography scan and CT; ROC: Receiver operating characteristic; TAMs: Tumor-associated macrophages; TNF: Tissue necrosis factor; VATS: Video-assisted thoracic surgery

\section{Acknowledgements}

We give sincere thanks to Weelic Chong, from the Sidney Kimmel Medical College/Thomas Jefferson University, Philadelphia, Pennsylvania, for language editing of this manuscript.

\section{Funding}

This work was supported by Key Science and Technology Program of Sichuan Province, China (2014SZ0148 to Dr. Weimin Li; 2016 FZ0118 to Dr. Lunxu Liu). No funding sources were involved in study design, data collection, data analysis, or the writing of the manuscript.

\section{Availability of data and materials}

The datasets generated and analyzed during the current study are not publicly available due to confidential agreement but are available from the corresponding author on reasonable request.

\section{Authors' contributions}

$Y H, L X L$ and $W M L$ conceptualized the study and critically read the manuscript. YH, NC, WWW, ZHW, FL, CLG and CWL performed and/or assisted surgery, managed patients, and participated in data analysis. $\mathrm{YH}$ and NC wrote the manuscript. All authors read and approved the final manuscript

\section{Ethics approval and consent to participate}

The study approval was approved by the Institutional Review Board at the West China Hospital, Sichuan University. All participants have signed the consent to patients for participating in this study.

\section{Consent for publication}

Not applicable.

\section{Competing interests}

The authors declare that they have no competing interests.

\section{Publisher's Note}

Springer Nature remains neutral with regard to jurisdictional claims in published maps and institutional affiliations.

\section{Author details}

'Department of Thoracic Surgery, West China Hospital, Sichuan University, Address: No. 37, Guoxue Alley, Chengdu 610041, Sichuan, China. ${ }^{2}$ West China School of Medicine, Sichuan University, Chengdu 610041, China.

${ }^{3}$ Department of Respiratory and Critical Care Medicine, West China Medical School/West China Hospital, Sichuan University, Chengdu, China.

\section{Received: 6 January 2018 Accepted: 8 October 2018}

\section{Published online: 22 October 2018}

\section{References}

1. Siegel RL, Miller KD, Jemal A. Cancer statistics, 2018. CA Cancer J Clin. 2018; 68(1):7-30. Epub 2018 Jan 4.

2. Balkwill F, Mantovani A. Inflammation and cancer: back to Virchow. Lancet. 2001;357:539-45.

3. Non-Small Cell Lung Cancer. In: Detailed Guide. The American Cancer Society 2016. http://www.cancer.org/cancer/lungcancer-non-smallcell/ detailedguide/index. Accessed 25 Oct 2016.

4. Coussens LM, Zitvogel L, Palucka AK. Neutralizing tumor-promoting chronic inflammation: a magic bullet. Science. 2013;339:286-91.

5. Shen SL, Fu SJ, Huang XQ, Chen B, Kuang M, Li SQ, Hua YP, Liang LJ, Peng BJ. Elevated preoperative peripheral blood monocyte count predicts poor prognosis for hepatocellular carcinoma after curative resection. BMC Cancer. $2014 ; 14: 744$
6. Porrata LF, Ristow K, Habermann TM, Witzig TE, Colgan JP, Inwards DJ, Ansell SM, Micallef IN, Johnston PB, Nowakowski GS, Thompson C, Markovic SN. Peripheral blood lymphocyte/monocyte ratio at diagnosis and survival in classical Hodgkin's lymphoma. Haematologica. 2012;97:262-9.

7. Kumagai S, Marumo S, Shoji T, Sakuramoto M, Hirai T, Nishimura T, Arima N, Fukui $\mathrm{M}$, Huang CL. Prognostic impact of preoperative monocyte counts in patients with resected lung adenocarcinoma. Lung Cancer. 2014;85:457-64.

8. Travis WD, Bramvilla E, Hk M-H, Harris CC. Tumours of the lung, pleura, thymus and heart. 4th ed. Lyon: International Agency for Research on Cancer; 2015.

9. Sobin LH, Gospodarowicz MK, Wittekind C. International Union against Cancer (UICC): TNM classification of malignant tumours. 7th ed. UK: Willkey; 2010

10. Dvorak HF, Weaver VM, Tlsty TD, Bergers G. Tumor microenvironment and progression. J Surg Oncol. 2011;103:468-74

11. Negus RP, Stamp GW, Hadley J, Balkwill FR. Quantitative assessment of the leucocyte infiltrate in ovarian cancer and its relationship to the expression of C-C chemokines. Am J Pathol. 1997;150(5):1723-34.

12. Badakhshi H, Kaul D, Zhao KL. Association between the inflammatory biomarker, C-reactive protein, and the response to radiochemotherapy in patients with esophageal cancer. Mol Clin Oncol. 2016:4:643-7.

13. Domínguez SA, Sierra FE, Puig KA, Pérez MB, Gómez AF, Corcuera MT, Sánchez MP, Corbí AL. Dendritic cell-specific ICAM-3-grabbing nonintegrin expression on M2-polarized and tumor-associated macrophages is macrophage-CSF dependent and enhanced by tumor-derived IL-6 and IL10. J Immunol. 2011;186:2192-200.

14. Gouyer V, Conti M, Devos P, Zerimech F, Copin MC, Créme E, Wurtz A, Porte $H$, Huet G. Tissue inhibitor of metalloproteinase 1 is an independent predictor of prognosis in patients with nonsmall cell lung carcinoma who undergo resection with curative intent. Cancer. 2005:103:1676-84.

15. Gandini S, Ferrucci PF, Botteri E, Tosti G, Barberis M, Pala L, Battaglia A, Clerici A, Spadola G, Cocorocchio E, Martinoli C. Prognostic significance of hematological profiles in melanoma patients. Int J Cancer. 2016;139:1618-25.

16. Kyoizumi S, Kubo Y, Kajimura J, Yoshida K, Hayashi T, Nakachi K, Young LF, Moore MA, van den Brink MR, Kusunoki Y. Linkage between dendritic and T cell commitments in human circulating hematopoietic progenitors. Immunol. 2014;192:5749-60.

17. Chen HW, Chen HY, Wang LT, Wang FH, Fang LW, Lai HY, Chen HH, Lu J, Hung MS, Cheng Y, Chen MY, Liu SJ, Chong P, Lee OK, Hsu SC. Mesenchymal stem cells tune the development of monocyte-derived dendritic cells toward a myeloid-derived suppressive phenotype through growth-regulated oncogene chemokines. J Immunol. 2013;190:5065-77.

18. Nguyen BA, Fiorentino F, Reeves BC, Baig K, Athanasiou T, Anderson JR, Haskard DO, Angelini GD, Evans PC. Mini bypass and Proinflammatory leukocyte activation: a randomized controlled trial. Ann Thorac Surg. 2016; 101:1454-63.

19. Fragiadakis GK, Gaudillière B, Ganio EA, Aghaeepour N, Tingle M, Nolan GP, Angst MS. Patient-specific immune states before surgery are strong correlates of surgical recovery. Anesthesiology. 2015;123:1241-55.

20. von Hohenstaufen KA, Conconi A, de Campos CP, Zucca E. Prognostic impact of monocyte count at presentation in mantle cell lymphoma. $\mathrm{Br}$ J Haematol. 2013;162:465-73.

21. Wilcox RA, Ristow K, Habermann TM, Inwards DJ, Micallef IN, Johnston PB, Colgan JP, Nowakowski GS, Ansell SM, Witzig TE, Markovic SN, Porrata L. The absolute peripheral monocyte count is associated with overall survival in patients newly diagnosed with follicular lymphoma. Leuk Lymphoma. 2012; 53:575-80.

22. Franke A, Lante W, Fackeldey V, Becker HP, Kurig E, Zöller LG, Weinhold C, Markewitz A. Pro-inflammatory cytokines after different kinds of cardiothoracic surgical procedures: is what we see what we know. Eur J Cardiothorac Surg. 2015;28:569-75.

23. Wu H, Xu JB, He YL, Peng JJ, Zhang XH, Chen CQ, Li W, Cai SR. Tumorassociated macrophages promote angiogenesis and lymphangiogenesis of gastric cancer. J Surg Oncol. 2012;106:462-8.

24. Jaipersad AS, Lip GY, Silverman S, Shantsila E. The role of monocytes in angiogenesis and atherosclerosis. J Am Coll Cardiol. 2014;63:1-11.

25. Kimura $H$, Esumi $H$. Reciprocal regulation between nitric oxide and vascular endothelial growth factor in angiogenesis. Acta Biochim Pol. 2003;50(1):49-59.

26. Pamukcu B, Lip GY, Devitt A, Griffiths H, Shantsila E. The role of monocytes in atherosclerotic coronary artery disease. Ann Med. 2010;42:394-403. 
27. González D, Domínguez S, Nieto C. Atypical Activin a and IL-10 production impairs human CD16+ monocyte differentiation into anti-inflammatory macrophages. J Immunol. 2016;196:1327-37.

28. Shantsila E, Wrigley B, Tapp L, Apostolakis S, Montoro-Garcia S, Drayson MT, Lip GY. Immunophenotypic characterization of human monocyte subsets: possible implications for cardiovascular disease pathophysiology. J Thromb Haemost. 2011;9:1056-66.

29. Sbrana S, Parri MS, De Filippis R, Gianetti J, Clerico A. Monitoring of monocyte functional state after extracorporeal circulation: a flow cytometry study. Cytometry. 2004;58B:17.

30. Schauer D, Starlinger P, Zajc P. Monocytes with angiogenic potential are selectively induced by liver resection and accumulate near the site of liver regeneration. BMC Immunol. 2014;15:50

31. Richards DM, Hettinger J, Monocytes FM. Macrophages in Cancer: development and functions. Cancer Microenviron. 2013;6(2):179-91 Epub 2012 Nov 24.

32. Hanna RN, Cekic C, Sag D, Tacke R, Thomas GD, Nowyhed H, Herrley E, Rasquinha N, McArdle S, Wu R, Peluso E, Metzger D, Ichinose H, Shaked I, Chodaczek G, Biswas SK, Hedrick CC. Patrolling monocytes control tumor metastasis to the lung. Science. 2015;350:985-90.

33. Mantovani A, Sozzani S, Locati M, Allavena P, Sica A. Macrophage polarization: tumor-associated macrophages as a paradigm for polarized M2 mononuclear phagocytes. Trends Immunol. 2002;23:549-55.

34. Qian BZ, Pollard JW. Macrophage diversity enhances tumor progression and metastasis. Cell. 2010;141:39-51.

35. Maeda R, Ishii G, Neri S, Aoyagi K, Haga H, Sasaki H, Nagai K, Ochiai A. Circulating CD14+CD204+ cells predict postoperative recurrence in nonsmall-cell lung cancer patients. J Thorac Oncol. 2014;9:179-8.

36. Giovino GA, et al. Tobacco use in 3 billion individuals from 16 countries: an analysis of nationally representative cross-sectional household surveys. Lancet. 2012;380(9842):668-79.

Ready to submit your research? Choose BMC and benefit from:

- fast, convenient online submission

- thorough peer review by experienced researchers in your field

- rapid publication on acceptance

- support for research data, including large and complex data types

- gold Open Access which fosters wider collaboration and increased citations

- maximum visibility for your research: over $100 \mathrm{M}$ website views per year

At $\mathrm{BMC}$, research is always in progress.

Learn more biomedcentral.com/submissions 